\title{
Impact of egg donation deliveries from domestic and overseas sources on maternal care: a questionnaire survey of Japanese perinatal physicians
}

\author{
Yuri Hibino $\cdot$ Yosuke Shimazono
}

Received: 15 November 2013/Accepted: 17 March 2014/Published online: 4 April 2014

(C) The Japanese Society for Hygiene 2014

\begin{abstract}
Objectives Recent demographic changes, such as marriage at later ages and delayed childbearing, have contributed to the increased demand for ovum donation. The purpose of the present study was to evaluate the frequency and impact of egg donation deliveries on maternal care using a questionnaire survey of Japanese perinatal care providers.

Methods A quantitative survey was conducted from October to November 2012 using self-administered anonymous questionnaires. We asked 2,693 obstetrics clinics/ hospitals throughout Japan to complete the survey: 679 questionnaires were returned (response rate, $25.2 \%$ ).

Results Of the respondents, $15.8 \%$ answered that they had handled egg donation deliveries in the past. With regards to the country in which patients received egg donation services, the most frequent was the United States, including Hawaii. Asian countries, such as Thailand, Korea, and Singapore, were also reported; only two cases in Japan were reported. "Advanced age/menopause" was the most frequent reason for egg donation, and the mean age at egg donation delivery, because of advanced age/ menopause, was 48.3 years.

Conclusions Our findings will increase public awareness of the legal issues related to assisted reproductive technology and cross-border reproductive care, as well as care of the mother and child in pregnancies resulting from reproductive technologies such as egg donation overseas. People should be aware of the issues involved in egg
\end{abstract}

Y. Hibino $(\bowtie) \cdot$ Y. Shimazono

Department of Environmental and Preventive Medicine,

Graduate School of Medical Science, Kanazawa University,

Kakumamachi, Kanazawa 920-1192, Japan

e-mail: hibino@staff.kanazawa-u.ac.jp donation abroad and the resulting deliveries, and should implement specific care for women bearing children at later ages.

Keywords Japanese patients - Egg donation delivery · Infertility · Obstetricians · Late childbearing

\section{Introduction}

Recent demographic changes, such as marriage at later ages and delayed childbearing, have contributed to the increased demand for assisted reproductive technology (ART) in Japan. Indeed, in Japan, around 600 accredited in vitro fertilization (IVF) clinics performed over 200,000 IVF cycles in 2009 [1].

The dissemination of ART in Japan has contributed to an increase in child deliveries at advanced ages. Advanced maternal age, defined as 35 years or older at the estimated delivery date, has become increasingly common in Japan. The number of live births in women aged 45-49 years and older in Japan increased from 244 to 802 between 1985 and 2011. The number of deliveries by women older than 50 years rose from only one in 1985 to 41 in 2011 [2].

This increase in childbearing at later ages has been supported not only by the increasing use of IVF but also by an increase in infertile patients who receive donor-egg IVF. Ova donated by younger women enable older women to conceive. According to statistical data from the Centers for Disease Control and Prevention [3], the live birth rate of women who had undergone standard, non-donor IVF decreases with increasing age. Conversely, the live birth rate of women who had undergone donor-egg IVF was approximately stable with age. Even postmenopausal women can conceive if the ovum comes from a younger 
woman. Thus, egg donation may contribute to an increased frequency of very late childbirth.

The use of donor eggs in infertility treatment has contributed to the availability of procreative choices for older women. At the same time, this practice remains controversial. Several countries have legal restrictions on such procedures, whereas commerce in donor oocytes is flourishing in other countries.

No comprehensive ART legislation exists in Japan, and regulation of third-party reproduction is left to professional bodies or is based on governmental reports. Regarding egg donation, the Japan Society of Obstetrics and Gynecology (JSOG) published guidelines in 2004 [4], as did the Japan Society for Reproductive Medicine (JSRM) in 2009 [5]. Both state that commercial egg donation should be prohibited, and only 'altruistic' donation should be permitted. The Japanese Institution for Standardizing Assisted Reproductive Technology (JISART) was organized by the private sector in 2003 in the context of a lack of altruistic egg donors. JISART formulated its own guidelines, and its member clinics established a voluntary egg donation program among relatives (e.g., sisters) of recipients [6]. However, only $18 \mathrm{egg}$ donations were reported between 2008 and 2011. JISART is the only organization that discloses its operations; the number of egg donations received by other clinics in Japan is unknown.

However, it is difficult for patients to access donor eggs for IVF in Japan. Consequently, increasing numbers of Japanese women have traveled overseas. This phenomenon has been referred to as "reproductive tourism" [7] and "cross-border reproductive care" [8, 9]. Japanese patients unable to access to donor eggs have usually traveled to the United States, but increasing numbers of Japanese women also travel to Asian countries, such as India, Thailand, Malaysia, and South Korea.

With the development of reproductive tourism, Japanese perinatal specialists now encounter an increasing number of Japanese patients who have undergone embryo transfer abroad and then returned to Japan for delivery. They must deal with patients who face possible medical risks associated with advanced maternal age and egg donation.

The purpose of the present study was to evaluate the frequency and impact of egg donation delivery on maternal care, based on data from questionnaires completed by Japanese perinatal care providers. Many previous surveys focused primarily on the attitudes of infertility specialists regarding ART and third-party reproduction [10-13]. Such studies have discussed access to ART: which women access ART services, what types of technologies should be provided, and whether the right to identify children born from third-party reproduction should be accepted. To date, however, few studies have reported on the attitudes, opinions, and perceptions of perinatal specialists who must offer perinatal care to patients seeking reproductive services from ART and third-party providers. This study focused on perinatal care specialists' attitudes toward, opinions about, and perceptions of ART [14-16], the frequency and the details of egg donation delivery [17] and cross-border reproductive care [18].

\section{Materials and methods}

Data collection and analysis

The present study was approved by the Ethics Committee of the Kanazawa Graduate School of Medical Sciences (No. 1274).

A quantitative survey was conducted using a selfadministered anonymous questionnaire. From October to November 2012, we asked 2,693 obstetrics clinics/hospitals throughout Japan to complete our survey. The list of clinics/hospitals was drawn from the website http://shu sanki.org/area.html. The list contains all the facilities where women can deliver in Japan. Completed questionnaires were sealed in a white envelope and returned to the hospital or mailed directly to the researchers by each respondent. The questionnaire in English is available at the website http://saisentan.w3.kanazawa-u.ac.jp/image/syuu sanki_en.pdf (password: SGRH), and the Japanese version at http://saisentan.w3.kanazawa-u.ac.jp/image/suvey_Inves tigation.pdf (password: SGRH).

Calculations, including descriptive analyses, were performed using the SPSS software (ver. 19.0 for Mac). To evaluate differences between categories, a $\chi^{2}$ test was used. To examine differences in mean values between more than two groups of variables, ANOVA was used. $p$ values $<0.05$ were deemed to indicate statistical significance.

\section{Assessment}

Demographic characteristics of obstetricians (age, gender, marital status, and years of experience in obstetrics) and institutional background (NICU, institutional type, and number of deliveries per year) were obtained.

The past experience of respondents with egg donation pregnancies was evaluated. The question was "Have you had any patients who became pregnant via egg donation?" The response could be "Yes" or "No."

Next, respondents were asked how they would handle an egg donation pregnancy case. The four options were "Provide no special care," (meaning no extra/different care specific to egg donation delivery), "Refer to another hospital," "Provide special care, such as hospitalization," and "Refuse delivery." 
Recognition of the involved risks was assessed with the following question: "Do you think pregnancy via egg donation carries risks for the recipient (regardless of age)?" The response could be "Yes," "No," or "Do not know."

We inquired about the annual number of egg donation deliveries performed during the previous 5 years (2007-2011). Each respondent was asked to describe the 10 most recent cases in detail (including the reason for egg donation and the country where the reproductive services were provided).

Regarding age-related matters, respondents were asked whether there should be an age limit for the ovum recipient. The answers were "Agree with an age limit," "Disagree with an age limit," or "Disagree with egg donation." If they agreed with an age limit for the recipient, respondents were also asked what the limit should be. Moreover, respondents were asked the age of the oldest patient for whom they performed a delivery, and what the upper age limit for a safe delivery should be.

\section{Results}

Individual characteristics and institutional background information

In this study, 679 questionnaires were returned, for a response rate of $25.2 \%$. The clinics covered six major regions in Japan. The distribution and response rates (\%) according to region were as follows: $87(30.6 \%)$ in the Chugoku and Shikoku regions, $124(26.2 \%)$ in the Chubu region, $125(26.0 \%)$ in the Kinki region, 78 (24.0\%) in the Hokkaido and Tohoku regions, 124 (23.8\%) in the Kanto region, and 97 (22.8\%) in the Kyushu and Okinawa regions. The distribution and response rates according to institutional type were as follows: obstetrics and gynecology (OB/GYN) clinics, $n=357$ and 52.6\%; OB/GYN departments at general hospitals, $n=211$ and $31.1 \%$; OB/ GYN departments at university hospitals, $n=47$ and $6.9 \%$; and perinatal medical centers $n=46$ and $6.8 \%$.

Individual characteristics and institutional background information are presented in Table 1. The distribution of the participants' ages was as follows: 50-59 (40.9\%), 40-49 (27.0\%), 60-69 (22.1\%), 30-39 (5.6\%), 70-79 $(4.3 \%)$, and 20-29 (0.1\%). In total, $593(87.5 \%)$ were males, and most of the respondents $(93.1 \%)$ were married. The mean experience ( \pm standard deviation, SD) in perinatal care was $27.3 \pm 9.2$ years. Regarding the institutional number of deliveries per year, most $(62.1 \%)$ had 100-499, and $25.7 \%$ had 500-999. The percentage of hospitals/clinics with a neonatal intensive care unit (NICU) was $19.6 \%$.
Table 1 Individual characteristics and institutional characteristics ( $n=679)$

\begin{tabular}{|c|c|c|c|}
\hline & & $n$ & $\%$ \\
\hline Gender & Male & 593 & 87.5 \\
\hline Marital status & Married & 632 & 93.1 \\
\hline \multirow[t]{6}{*}{ Age } & $20-29$ & 1 & 0.1 \\
\hline & $30-39$ & 38 & 5.6 \\
\hline & $40-49$ & 183 & 27.0 \\
\hline & $50-59$ & 278 & 40.9 \\
\hline & $60-69$ & 150 & 22.1 \\
\hline & $\geq 70$ & 29 & 4.3 \\
\hline $\begin{array}{l}\text { Years of experience in } \\
\text { obstetrics }\end{array}$ & $<10$ & 14 & 2.0 \\
\hline \multirow[t]{4}{*}{$27.3( \pm 9.2)$} & $10-20$ & 105 & 15.5 \\
\hline & $20-30$ & 273 & 40.2 \\
\hline & $30-40$ & 209 & 30.8 \\
\hline & $\geq 40$ & 78 & 11.5 \\
\hline NICU & Yes & 133 & 19.6 \\
\hline \multirow{5}{*}{$\begin{array}{l}\text { Type of medical } \\
\text { institution }\end{array}$} & OB/GYN Clinic ${ }^{\mathrm{a}}$ & 357 & 52.6 \\
\hline & $\begin{array}{l}\text { OB/GYN Department at } \\
\text { University Hospital }\end{array}$ & 47 & 6.9 \\
\hline & $\begin{array}{l}\text { OB/GYN Department at } \\
\text { General Hospital }\end{array}$ & 211 & 31.1 \\
\hline & Perinatal Medical Center & 46 & 6.8 \\
\hline & Other & 18 & 2.6 \\
\hline \multirow{5}{*}{$\begin{array}{l}\text { Number of deliveries } \\
\text { per year }\end{array}$} & $<100$ & 48 & 7.2 \\
\hline & $100-499$ & 420 & 62.1 \\
\hline & 500-999 & 174 & 25.7 \\
\hline & $1,000-1,999$ & 32 & 4.7 \\
\hline & $>2,000$ & 2 & 0.3 \\
\hline
\end{tabular}

a Obstetric and gynecology clinic

Past experience, attitudes towards patients, and recognition of risks

Participants were asked about their past experiences with egg donation delivery (Fig. 1). Of all respondents, 107 (15.8\%) responded that they had experience with an egg donation delivery. However, more than $80 \%(83.8 \%)$ had no such experience. Among them, $60.0 \%$ of respondents affiliated with a university hospital and $56.8 \%$ of respondents affiliated with a perinatal medical center had experience with egg donation deliveries. Thus, approximately one in six obstetricians had previously encountered deliveries resulting from donor-egg IVF.

Respondents were also asked how they proceeded once an egg donation pregnancy was identified. There was a difference between obstetricians who had previously handled an egg donation delivery and those who had not $(p<0.001$; Table 2). Among respondents who had experience with egg donation delivery, more than $80 \%$ 
non

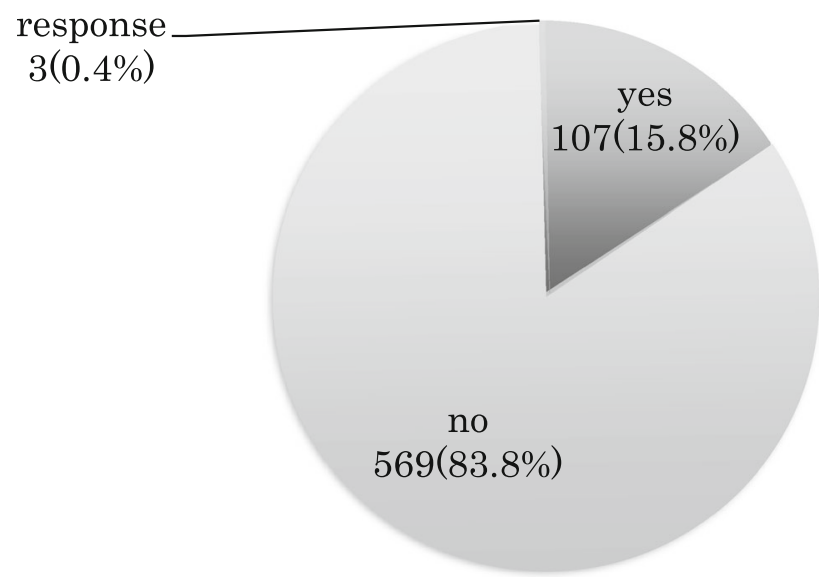

Fig. 1 Have you had any patients who were pregnant via egg donation?

responded that they provided no special care for the patient. In contrast, among respondents who had no experience with egg donation delivery, $56.4 \%$ responded that they would offer no special care to the patient, $26 \%$ responded that they would refer the patient to another hospital/clinic, $4.7 \%$ responded that they would refuse the patient, and $3.7 \%$ responded that they would hospitalize and provide special patient management.

Regarding recognition of the risks associated with egg donation delivery, more than half of respondents $(54.3 \%)$ with experience with egg donation delivery agreed that the procedure was risky. In contrast, of the respondents with no experience of egg donation delivery, $42.8 \%$ responded "Do not know" ( $p<0.001$; Table 2$)$.

Egg donation delivery cases

The number of egg donation deliveries reported by obstetricians was 20 in 2007, whereas 63 were reported in 2011 (Table 3); thus, a threefold increase occurred in the 5-year period. Respondents were asked to describe 91 of the 169 cases in detail. In total, 107 reasons for egg donation were reported and are described here. For 53 cases, "advanced age/menopause" was the reason reported for egg donation. Repeated failure of IVF was described for 17 cases, premature menopause for 13 cases, and unknown cause for 19 cases. Regarding the country in which patients received egg donation services, the most frequent was the United States, including Hawaii (91 cases) (57). Asian countries, such as Thailand (7), Korea (6), and Singapore (1), were also reported. Only two cases were reported in Japan. Regarding the number of deliveries of fetuses, $33 \%$ of the 91 cases were multiple pregnancies (Table 3 ).

Association of age with procedure safety

The age of the oldest patient for whom the respondents had experienced a delivery ranged from 36 to 60 years (mode, 45 years). Moreover, more than half of the respondents $(61.5 \%)$ had experienced a delivery from a patient older than 45 years (Table 4). The age of the oldest patient differed according to institution type. The average age of the

Table 2 Attitudes toward and perceptions of egg donation delivery among respondents

\begin{tabular}{|c|c|c|c|}
\hline & $\begin{array}{l}\text { Doctors with experience with deliveries for } \\
\text { patients receiving egg donation }\end{array}$ & $\begin{array}{l}\text { Doctors without experience with deliveries for } \\
\text { patients receiving egg donation }\end{array}$ & Total \\
\hline \multicolumn{4}{|c|}{ Response to patients who were pregnant through egg donation $\dagger$} \\
\hline Provide no special care & $84(80.8)$ & $291(56.4)$ & $375(60.5)$ \\
\hline Refer to other hospitals & $8(7.7)$ & $134(26.0)$ & $142(22.9)$ \\
\hline $\begin{array}{l}\text { Provide special care such } \\
\text { as hospitalization }\end{array}$ & $8(7.7)$ & $19(3.7)$ & $27(4.4)$ \\
\hline Refuse delivery & $1(1.0)$ & $24(4.7)$ & $25(4.0)$ \\
\hline Other & $3(2.8)$ & $48(9.2)$ & $51(8.2)$ \\
\hline Total & $104(100.0)$ & $516(100.0)$ & $620(100.0)$ \\
\hline \multicolumn{4}{|c|}{ Do you think pregnancy via egg donation carries risks for the recipient (regardless of age)? $\oint$} \\
\hline Yes & $57(54.3)$ & $240(44.8)$ & $297(46.3)$ \\
\hline No & $19(18.1)$ & $63(11.7)$ & $82(12.8)$ \\
\hline Do not know & $27(25.7)$ & $230(42.8)$ & $257(40.0)$ \\
\hline Other & $2(1.9)$ & $4(0.7)$ & $6(0.9)$ \\
\hline Total & $105(100.0)$ & $537(100.0)$ & $642(100.0)$ \\
\hline
\end{tabular}

$\dagger$ Chi square test: $p<0.001$

$\oint$ Chi square test: $p<0.001$ 
oldest patient at perinatal medical centers was 48.4 years, and that at university-affiliated hospitals was 48.6 years. These two ages were higher than those of both general hospitals (45.6 years) and free-standing private clinics (44.6 years; Fig. 2, $p<0.001$ ).

According to the physicians' opinions, the upper age limit for safe delivery ranged from 30 to 53 years. More

Table 3 Egg donation delivery cases

\begin{tabular}{ll}
\hline Number of pregnancies via egg donation & $(n=169)$ \\
2007 & 20 \\
2008 & 23 \\
2009 & 26 \\
2010 & 37 \\
2011 & 63 \\
Reasons for egg donation (\%) & $(n=107)$ \\
Advanced age/menopause & 53 \\
Repeated failure of IVF & 17 \\
Premature menopause (including Turner syndrome) & 13 \\
Anovulation & 2 \\
Ovariectomy & 2 \\
Other (ovarian dysfunction by kidney transplant) & 1 \\
Unknown & 19 \\
Total was not 91 because of multiple answers & \\
Country where patients received egg donation services & $(n=91)$ \\
Number of patients by destination country & \\
US (Hawaii 3) & 57 \\
Thailand & 7 \\
Korea & 61 \\
Japan & 28 \\
Singapore & 2 \\
Russia & 17 \\
Unknown & 1 \\
Number of fetus & 2 \\
Single & \\
Twin & \\
Triplet & 17 \\
\hline
\end{tabular}

than half of the respondents $(53.7 \%)$ answered that the safe delivery age was up to 45 years old, while 189 $(30.1 \%)$ responded up to 40 years old (Table 4$)$.

Regarding ovum donation, over half of the respondents $(54.6 \%)$ agreed with limiting the age for ovum recipients. In contrast, $33.2 \%$ of respondents were against egg donation itself. There was a significant difference between male and female respondents regarding age limits. More female $(71.8 \%)$ than male $(52.1 \%)$ respondents agreed with an age limit (Fig. 3).

The upper age limit for ovum recipients was determined among respondents who agreed with limiting ovum donation by age $(n=343)$. The age limit ranged from 29 to 55 years. Of the respondents, $126(36.7 \%)$ responded that ovum donation should be performed in recipients aged 45 years or younger and $100(29.2 \%)$ responded that ovum donation should be performed in recipients aged 40 years or younger (Table 4).

\section{Discussion}

In the present study, one of six respondents (15.8\%) reported experience with egg donation delivery. Moreover, the total number of egg donation deliveries during the previous 5 years was 169 . However, this might represent only a small subset of cases because some women may choose not to inform their perinatal physicians, and the overall response rate was only $25.2 \%$. Moreover, egg donation delivery at an older age might occur more frequently in university hospitals and perinatal medical centers; however, the response rates at these types of institution were low. This could have resulted in underestimating egg donation delivery cases and creating bias regarding the age of egg donation delivery. Although the precise number of egg donation deliveries in Japan is unknown, it may have increased in recent years in accordance with the increase in late childbearing generally. In

Table 4 Respondents' experiences with and perceptions of maternal age

\begin{tabular}{|c|c|c|c|c|c|c|c|c|c|}
\hline & Lowest & Highest & $\begin{array}{l}\text { Mean } \\
( \pm \text { SD })\end{array}$ & Mode & $\begin{array}{l}\text { Up to } 35 \\
(\%)\end{array}$ & $\begin{array}{l}\text { Up to } 40 \\
(\%)\end{array}$ & $\begin{array}{l}\text { Up to } 45 \\
(\%)\end{array}$ & $\begin{array}{l}\text { Up to } 50 \\
(\%)\end{array}$ & $\begin{array}{l}\text { Over } 50 \\
(\%)\end{array}$ \\
\hline Oldest maternal age at delivery (670) & 36 & 60 & $\begin{array}{l}45.3 \\
\quad( \pm 2.9)\end{array}$ & 45 & 0 & $9(1.3)$ & $395(59.0)$ & $228(34.0)$ & $38(5.7)$ \\
\hline Upper age limit for safe delivery (628) & 30 & 53 & $\begin{array}{l}43.2 \\
\quad( \pm 3.5)\end{array}$ & 45 & $22(3.5)$ & $189(30.1)$ & $337(53.7)$ & $79(12.6)$ & $1(0.1)$ \\
\hline Upper age limit for ovum recipients (343) & 29 & 55 & $\begin{array}{l}41.5 \\
\quad( \pm 5.1)\end{array}$ & 45 & $\begin{array}{l}64 \\
(18.7)\end{array}$ & $100(29.2)$ & $126(36.7)$ & $33(9.6)$ & $20(5.8)$ \\
\hline Age at egg donation delivery (91) & 26 & 58 & $\begin{array}{l}44.6 \\
( \pm 7.0)\end{array}$ & 46 & $\begin{array}{l}14 \\
(15.4)\end{array}$ & $6(6.6)$ & $18(19.8)$ & $38(41.8)$ & $15(16.4)$ \\
\hline $\begin{array}{l}\text { Age at egg donation delivery (advanced } \\
\text { age/menopause) (53) }\end{array}$ & 39 & 58 & $\begin{array}{l}48.3 \\
\quad( \pm 3.6)\end{array}$ & 47 & 0 & $2(3.8)$ & $9(17.0)$ & $29(54.7)$ & $13(24.5)$ \\
\hline
\end{tabular}


Fig. 2 The average age of the oldest patient

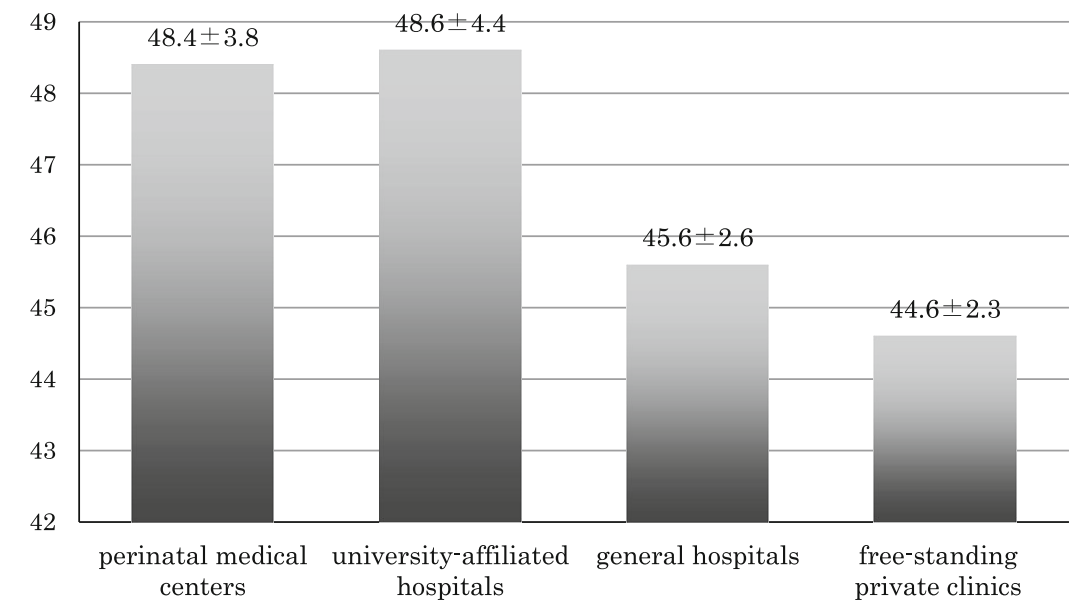

statistical test: one way ANOVA $(\mathrm{p}<0.001)$

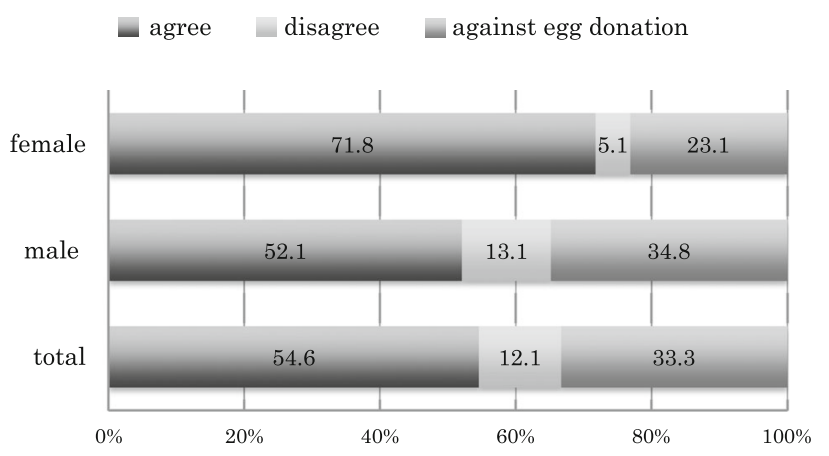

statistical test: chi-square $(\mathrm{p}=0.004)$

Fig. 3 Age limit for egg donation

the present study, the number of egg donation deliveries increased linearly during the previous 5 years (Table 2). Measures to protect maternal and child health resulting from egg donation deliveries should be implemented immediately.

The reason that women hesitate to reveal that they have undergone an egg donation procedure is that infertility is stigmatized in Japanese society, and few egg donations are performed domestically. Consequently, although egg donation is not illegal in Japan, the status of egg donation procedures remains ambiguous to many. Thus, women who have received IVF with donor eggs may feel unable to report the fact to their perinatal doctors. Another reason may be that several clinics/hospitals refuse to provide delivery services if a pregnancy resulted from ovum donation. In the present study, $4.7 \%$ of perinatal professionals with no experience of egg donation cases responded that they would refuse to accept such women. In contrast, of the physicians with experience of egg donation delivery, none reported providing special care. This result must be interpreted with caution. Japanese perinatal physicians affiliated with a university hospital or perinatal medical center treat many pregnant women with high-risk factors, such as older age; thus, they may have answered "give no special care" for this question. Based on these facts, specific guidelines for the care of egg donation deliveries should be established in Japan.

Egg donation by younger women enables older women to conceive. Thus, a proportion of egg donation deliveries tended to involve women who had children later in life. In the present study, more than half of the reported cases responded with "advanced age/menopause" as the reason for egg donation. Moreover, in the present study, the mean age of women who underwent an egg donation procedure at an advanced age was 48 years. This was higher than 45 years, which many physicians regarded as the age limit for delivery safety. Previous studies have explored whether egg donation delivery increases the risk of pregnancyinduced hypertension (PIH) [19]. In addition to donatedegg pregnancy, there may be other medical risk factors related to older age, such as miscarriage and placenta previa. In the present study, more than half of physicians $(54.3 \%)$ regarded egg donation delivery as risky, particularly among those who had experience with egg donation procedures. However, if patients do not disclose their status, clinicians cannot prepare for any extra risk associated with ovum donation. Thus, concealing having undergone an egg donation procedure may be risky behavior too.

In the present study, more than half of the respondents $(54.7 \%)$ agreed with limiting the age of ovum recipients. Domestically, egg donation is permitted for medical reasons, such as premature menopause, Turner syndrome, and anovulation, but not for advanced age alone. However, the advanced age threshold is difficult to identify. In reality, in the present study, the mean age of egg donation delivery 
due to advanced age was 48 years. Thus, if the Japanese government does not permit egg donation delivery because of advanced age, reproductive tourism will thrive and the deliveries at advanced ages will continue.

Cross-border reproductive care is motivated by several reasons. The major reason may be simply that people cannot obtain certain reproductive services domestically. A social trend towards increasingly late childbearing in Japan, coupled with the unavailability of donor eggs in this country, has contributed to increased demand for egg donation. Because very little ovum donation is conducted in Japan, many infertile patients go abroad, including the United States and Asian countries, and most of these patients give birth after their return to Japan.

Travel to seek third-party reproductive care such as egg donation is associated with medical, ethical, legal, and social problems. In terms of medical problems, reproductive tourism is associated with risks such as multiple pregnancies [18], and pregnancy at older ages. For example, of the 91 egg donation delivery cases reported in the present study, 28 cases were twins and 2 were triplets (Table 3). Regarding age, "Advanced age/menopause" was the most frequent reason for egg donation in the present study, and the mean age at egg donation delivery was 48.3 years for this reason, although $87.3 \%$ of respondents answered that the maximum age for safe delivery is up to 45 years old. As a result, measures to protect maternal and child health in the context of egg donation delivery should be implemented. In terms of social problems, unclear gamete donation records are common abroad. In terms of ethical problems, such travel might result in harm to economically vulnerable women. Moreover, legal problems may arise if there is any legal discrepancy between the two countries involved. Thus, policies regarding third-party reproductive care, such as age limit for egg donation delivery and ART and a legal system governing egg donation, including rights of the born child, should be developed.

The present study has several limitations and strengths. First, our overall response rate was low and the sample size was small. The response rate of perinatal medical centers was particularly low, and perinatal medical centers are likely especially important for egg donation deliveries. This may have introduced selection bias into the data, leading to misrepresentation of the extent of egg donation pregnancies and misinterpretation of the results, such as the total number of physicians who have delivery experience of egg donated pregnant women and the mean age at egg donation delivery. This may have caused underestimating egg donation delivery cases and a lower mean age for egg donation delivery cases. Thus, the results of the present study may not be representative of the overall frequency of egg donation deliveries in Japan. Nevertheless, delivery resulting from ovum donation, both domestically and overseas, is an urgent issue in Japan where, with trends towards marriage at later ages and delayed childbearing, demand for ART continues to increase. This is the first reported comprehensive nationwide study of Japanese obstetricians regarding egg donation delivery.

In summary, there are many issues regarding future perinatal care related to ART, including whether permission should be required for egg donation procedures due to advanced age, whether egg donation delivery should be performed domestically when pregnancy resulted from cross-border reproductive care, and what constitutes the provision of adequate maternal and child care in such cases. Hopefully, our findings will increase public awareness of the lack of care and legal systems related to ART, reproductive tourism, and care of the mother and child in cases of pregnancies resulting from reproductive technology.

Conflict of interest The authors declare that they have no conflict of interest.

\section{References}

1. Japan Society of Obstetrics and Gynecology (JSOG). Report on fertilization and embryo transfer in 2009. http://plaza.umin.ac. jp/ jsog-art/20121017data1.pdf. Accessed 29 Mar 2013, (Japanese).

2. Japan Ministry of Health, Labour and Welfare (JMHLW). Report on Birth Statistics 2011.http://www.mhlw.go.jp/toukei/saikin/hw/ jinkou/geppo/nengai11/toukei03.html. Accessed 29 Mar 2013, (Japanese).

3. Centers for disease control and prevention. Assisted reproductive technology; success rates, national summary and fertility clinic reports 2009: percentages of transfers that resulted in live birth for ART cycles using fresh embryos from own eggs and ART cycles using fresh embryos from donor eggs, by age of woman. http://www.cdc.gov/art/ART2009/sect4_fig46-50.htm\#f47. Accessed 29 Mar 2013, (Japanese).

4. Japan Society of Obstetrics and Gynecology (JSOG). Guidelines on Embryo Donation for Reproductive Purposes 2004. http://www. jsog.or.jp/about_us/view/html/kaikoku/H16_4.html. Accessed 29 Mar 2013, (Japanese).

5. Japan Society for Reproductive Medicine (JSRM). Guidelines on ART using third-party gamete 2009. http://www.jsrm.or.jp/ guideline-statem/guideline_2009_01.html. Accessed 29 Mar 2013, (Japanese).

6. Japanese Institution of Standardizing Assisted Reproductive Technology (JISART). Guideline for in vitro fertilization using donor sperm or donor egg 2008. http://www.jisart.jp/120831tai gai2.pdf. Accessed 29 Mar 2013, (Japanese).

7. Deonandan R, Green S, van Beinum A. Ethical concerns for maternal surrogacy and reproductive tourism. J Med Ethics. 2012;38(12):742-5.

8. Pennings G, de Wert G, Shenfield F, Cohen J, Tarlatzis B, Devroey P. ESHRE task force on ethics and law 15: cross border reproductive care. Hum Reprod. 2008;23(10):2182-4.

9. Ferraretti AP, Pennings G, Gianaroli L, Natali F, Magil MC. Cross-border reproductive care: a phenomenon expressing the 
controversial aspects of reproductive technologies. Reprod Biomed Online. 2010;20:261-6.

10. Bonetti TC, Melamed RM, Braga DP, Madaschi C, Iaconelli A Jr, Pasqualotto FF, et al. Assisted reproduction professionals' awareness and attitudes towards their own IVF cycles. Hum Fertil (Camb). 2008;11(4):254-8.

11. Khalili MA, Isikoglu M, Tabibnejad N, Ahmadi M, Abed F, Parsanejad ME, et al. IVF staff attitudes towards oocyte donation: a multi-centric study from Iran and Turkey. Reprod Biomed Online. 2008;17(Suppl 3):61-6.

12. Lampic C, Skoog Svanberg A, Sydsjö G. Attitudes towards gamete donation among IVF doctors in the Nordic countries-are they in line with national legislation? J Assist Reprod Genet. 2009;26(5):231-8.

13. Sperling D, Simon Y. Attitudes and policies regarding access to fertility care and assisted reproductive technologies in Israel. Reprod Biomed Online. 2010;21(7):854-61.

14. Lawrence RE, Rasinski KA, Yoon JD, Curlin FA. Obstericiangynecologists' beliefs about assisted reproductive technologies. Obstet Gynecol. 2010;116(1):127-35.
15. Svanverg AS, Shdsjo G, Selling KE, Lampic C. Attitudes towards gamete donation among Swedish gynaecologists and obstetricians. Hum Reprod. 2008;23(4):904-11.

16. Yogev Y, Simon Y, Ben-Haroush A, Simon D, Orvieto R, Kaplan B. Attitudes of Israeli gynecologists regarding candidate screening and personal responsibility in assisted reproductive technologies versus adoption in Israel. Eur J Obstet Gynecol Reprod Biol. 2003;110(1):55-7.

17. Nakayama S, Adachi T. Perinatal management and its problems of pregnancies achieved by donor egg in vitro fertilization. Cure Obstet Gynecol. 2011;203(4):383-8.

18. McKelvey A, David AL, Shenfield F, Jauniaux ER. The impact of cross-border reproductive care or 'fertility tourism' on NHS maternity services. BJOG. 2009;116(11):1520-3.

19. Wiggins DA, Main E. Outcomes of pregnancies achieved by donor egg in vitro fertilization-a comparison with standard in vitro fertilization pregnancies. Am $\mathrm{J}$ Obstet Gynecol. 2005;192(6):2002-6. 